\title{
Condolence in Classroom Teaching: Iraqi EFL University Students' Pragmatic Deviation
}

\author{
Kamal Hasan Jawad \\ College of Languages /University of Baghdad lamak7@gmail.com
}

\begin{abstract}
Research studies concerning pragmatic acquisition by students have established that pragmatic nonconformity or deviation in the execution of speech acts, among which is "condolence", is primarily due to the students' incompetence to identify the proper meaning and to handle the proper form. In Iraqi context, most Iraqi EFL university students are found to inapproriately use illocutionary acts, as they digress from the sociocultural standards and pragmalinguistic rules used for making condolence. When producing circumstances comprising the use of the expressive condolence, students' speeches and responses do not conform to those of native speakers. Their replies seem awkward or refer to certain spoken situations other than those required in the communicative process or interaction. Thus, the study intends to identify Iraqi EFL students' deviation in the performance of the expressive condolence in order to get at the reasons behind this unconventionality. To achieve this aim, fifty Iraqi EFL college students of the University of Baghdad, College of Languages, Department of English, have been chosen to give ( data) replies to a test containing five situtations involving the production of condolence. Responses to the test have shown that negative transfer of L1 sociopragmatic knowledge and lack of pragma-linguistic rules are the main characteristics that EFL Iraqi students resort to when handling condolence. Socio-pragmatic deviation occurs because they are linguistically unconscious of the conventions and means used in the target language; therefore, their performance is a non-native one. Further, lack of syntactic and semantic knowledge is an influential factor in producing certain spoken situations of condoling.
\end{abstract}

Keywords:

EFL University Students, Speech Acts, Expressives, Pragmatic Deviation, Condolence

Article Received: 18 October 2020, Revised: 3 November 2020, Accepted: 24 December 2020

\section{Introduction}

It is often realized that using a language implicates "not only knowledge of grammar, phonology" and vocabulary, "but also knowledge of certain features and characteristics" of society and culture which comprises a set of standards, norms, beliefs and philosophies that L2 speakers accept (Dascal, 1985: 96). This is often seen as one of the difficulties that Iraqi university students encounter while handling speech acts , that is, they rely on formal (grammatical) rather than on pragmatic (or social) features and principles when using speech acts in their daily communications.

Mostly, people are often called upon to express sympathy at somebody's death. Condolence, as an expressive speech act, is often employed to prompt the speaker's mourning and grief "at the news of someone's death", i.e. it permits the utterer "to share in the experience" and feelings of the receiver (Lotfollahi and Rasekh, 2011:140). Like other types of speech acts, condolence cannot be emotionally considered in separation from the situation and culture. In classroom settings, Iraqi non-native learners usually find difficulty in producing certain spoken situations involving the use of illocutionary act of condolence. One main reason behind this difficulty is owing to the pragmatic knowledge that most students lack. This knowledge is mainly attributed to the appropriateness of meaning in accordance with cultural and social settings in which condolence is used. Furthermore, this difficulty is also attributed to the students' lack of linguistic knowledge, as they fail to pinpoint the distinction between forms and functions (Cakir, 2006: 137).

Because of the differences between native ( English) and non-native ( Arabic) cultural principles and social norms, Iraqi students are supposed to suffer from the problem of using the speech acts of condolence and this might be considered an obstacle for efficient and effective 
communication. This statement is emphasized by Hurley (1992: 260) who confirms that pragmatic deviation "stems from nonconformity with values, attitudes, beliefs, and social norms and conventions, and having communicative competence in the target language should be one of the important tasks in the foreign language teaching classroom".

\section{Pragmatics: Speech Acts}

Pragmatics is mainly concerned with the use of language in appropriate social situation instead of limiting itself to the linguistically determined features of settings. The language users converse and produce language in terms of social principles. Based on this social perspective, Mey (2001: 6) maintains that "pragmatics studies the use of language in human communication as determined by the conditions of society".

Pragmatics, in this respect, is concerned with the communicative circumstances which influence language use. Put differently, the suitable scope of pragmatics is that which accounts for language use in everyday state of affairs. This interpretation is accentuated by Crystal's (2008: 398) who confirms that pragmatics:

"has come to be applied to the study
of language from the point of view of
the users, especially of the choices
they make, the constraints they
encounter in using language in social
interaction, and the effects their use
of language has on the other
participants in an act of
communication."

As a main component of pragmatics, the term 'speech acts' emanates from a theory commenced by Austin's "How to Do Things with Words" (1962). Speech acts theory is a straight rejection to rational traditions which "place truth conditions as dominant phenomenon to language understanding". Nunan (1999: 131) illuminates that speech acts are "simply things people do through language, for example, apologizing, complaining, instructing, agreeing and warning". Generally, 'speech act' is used in the study of language to signify a theory that studies the purpose of utterances with regard to "the behavior of speaker and hearer in interpersonal communication" (Crystal, 2009, s.v. speech act).

Laying emphasis on the socio-pragmatic and pragma-linguistic features, speech act theory is postulated to investigate "the linguistic conventions or procedures which govern all speech situations". These conventions designate the "social role which the speaker and the hearer assume for a certain speech act"; they are concerned with the language power utilized to shape the world but not to reflect it (Taylor, 1978: 357). In this context, speech acts theory is not connected to the grammatical structure of sentences in a language, but it is closely associated with the role and function that a certain communication is initiated for in the actual use of language.

Briefly, Black (2006:17f) maintains that speech acts theory works on the central idea that language is created principally for the purpose of communication, so that "specific ritualistic would have to be observed, the theory goes on the claim that the reasons for the functions of, or the communicative intentions can be classified" Consequently, any kind of reason, intention or function in social communication can be realized as a speech act as there is a purpose behind the speaker's message. On essential purpose of communication is conveying the speaker's feelings and emotions, i.e. expressive function.

\section{Expressives}

An expressive speech act is enunciated when a speaker wants to "express a psychological state" i.e. it reflects "what the speaker feels" (Yule, 1996: 53). Illustrative instances are when someone expresses appreciation or regret, or receives the hearer. Expressives are frequent in message panels as writers frequently salute readers at the commencement of a post "Hi everyone!" or express appreciation for support from the readers "I really appreciate the suggestions". Expressives (e.g. 
apologizing, congratulating and condoling) are one speech act category suggested by Searle's (1969 and 1976) important taxonomy, along with "Representatives, Directives, Commissives and Declaratives".

Elaborately, Mey (2001: 165) explicates that expressive speech acts reflect an internal "state of the speaker which in so far as it is essentially subjective says nothing about the world". Placed differently, Searle and Vanderveken (1985: 54) maintain that "utterances with the expressive illocutionary force have the null direction of fit", i.e. absence of direction of fit". Convincingly, Searle (1979: 5) makes clear that:

\section{"in performing an expressive the speaker is neither trying to get the world to match the words nor the words to match the world; rather the truth of the expressed preposition is presupposed. In general, there is no question or success or failure of and their propositional content is presupposed to be true. Therefore, illocutionary acts with the expressive force have the empty direction of fit."}

The central fact in issuing an expressive speech act is to reflect the speaker's mental state about a presented fact; he/she does not "attempt to establish a correspondence between words and things". In expressives, speakers only "want to manifest their feelings about the ways in which objects are in the world" (ibid). One type of expressives in which the speakers expresses his sadness, sorry and gloomy feeling is condolence.

\section{Condolence}

As an expressive illocutionary act, condolence is frequently used to reveal the speaker's sensation, feeling and excitement to a specific social matter. It reflects "the speaker's feelings about him/herself or the world" (Searle 1976: 12). For Norrick (1978: 279), an expressive speech act is delivered to articulate "psychological conditions, and thus not beliefs or intentions, which arise to give states of affairs". Elaborately, expressives are manipulated to echo "the state of mind, the attitudes, and the speakers' feelings of, uttering phrases such as, Okay, God blessings, sorry" (Taavitsainen, and Jucker, 2010: 159).

In performing expressive, the speaker wants to reflect "the psychological state specified in the sincerity condition about a state of affairs specified in the propositional content." Condolence is typically expressed in terms of indirect statements whose main functions are "invocation, wishing, request and beseech". It is identified as a category of expressives which represents "speaker's belief to a certain condition identified in the propositional contenting terms of Searle's conditions". They do not have any direction of fit because they are mere expressions of emotive and inner state of the speaker's mind (Allan, 1998:12).

More elaborately, Yahia (2010: 50f) confirms that condolence expressions are postulated to "convey sympathy for the bereaved person". Generally, the sentiment behind the expression is frequently "more important than the wording itself". In this sense, condolences are viewed as "formal expressions of sympathy offered to people after the death of a loved one". In common language use, condolence expressions include utterances like "sorry for your loss", "deepest sympathy".

From the semantic perspective, condolences, in most cases, predict a public meaning associated with language use, i.e., to maintain social rapports and purposes (Mwihaki, 2004: 133). Further, he proceeds to say that condolences are not merely "expressions of sympathy, they are also acts of encouragement". Participation in happy and sad occasions of other people enhances some traits such as social solidarity and group membership. One can rarely find a sympathetic expression in the direct speech act of condolence such a "I sympathize with you on the death of ...".Or " I condole you ...", because the hearer at time of loss in the utmost degree of depression and such expressions may 
increase the state of grief while the main function of condolence is to express relief.

Bach and Harnish (1979: 51) contend that the speech act of condolence is part of general category of acknowledgments which reflects the genuine feeling of the speaker towards the hearer. These speech acts are successfully performed when a particular occasion occurs for the hearer, when their assumptions are correct and there is a mutual shared knowledge between speaker/hearer. Condolence needs specifications about the mutual belief between the speaker and hearer, and pre- existence of a specific circumstance for the hearer. The speaker must know the exact occasion of death of someone, losing a valuable thing, etc. These facts are necessary in deciding the nature of condolence.

Because condolence is often associated with politeness, it is expressed in terms of indirect rather than direct speech act. The speech act condolence requires some respectable forms and polite expressions in order to be successfully performed. Any impolite behavior by the speaker (intended or not intended) may terminate the sense of sympathy and may increase the grief of the bereaved. Generally, death has very oppressive nature which obliges the speaker to be careful in the selection of expressions and styles. Therefore, it is better to adopt indirect speech acts because they have less degree of imposition on the hearer. Generally, in English, it is more acceptable to offer condolence through indirect forms (Fitzerald, 2003:4), such as:

- I am sorry.

- I feel sympathy with you.

- Please, accept my condolence. (Allan, 1998:12)

In English, it is not easy to convey or even to write condolence because most of these statements are derived from personal judgments and there are no fixed procedures for uttering them. People face many difficulties formulating in face condolences and sometimes may lose their concentration at that time. For this reason, Zunin and Zunin (2007: 13) acknowledge that "English people are unable to compose informative and adequate condolences."
Furthermore, they (ibid) affirm that people may become complete feeble or inactive to write down condolences in certain situations. The reason for this is that English people do not have sufficient information about the proper way of condolence though they "want to comfort, to condole", they "do not know what to write, what to say, or what to do". One justification for this is that "no one has ever taught us the art of condolence" (ibid, pp. 1-2).

\section{Pragmatic Deviation}

The main goal of second language learners is to attain effective communication conforming to native like speaker conversations. One main factor which hinders such communication is pragmatic failure or deviation. Pragmatic deviation is employed to point to learner's "inability to understand what is meant by what is said" (Thomas, 1983: 22). Principally, she attempts recognize what pragmatic failure is like. Based on Thomas' account, He Ziran (2006: 26) expounds that pragmatic deviation " does not refer to the general wording and phrasing errors that appear in language use, but rather refers to the failure to reach the expected result because of speaking improperly, expressing ideas in unidiomatic way". In the same vein, Guanlin (2002: 195) elaborates that pragmatic deviation occurs when:

"the speaker uses sentences with correct symbol relations in verbal communication, but speaks ill-timed, improperly or not habitually, he tends to unconsciously violate interpersonal norms, social conventions, or run counter to the sense of worth in the culture of target language by neglecting the time and space of communication, the identity and status of speakers and the occasion of communication, which leads to the barrier of the communication and results in the interruption of the communication and failure to achieve a satisfactory desired communicative aim." 
In some cases, pragmatic deviation may result in rather funny and anecdotal, yet in others it may cause misunderstandings leading to "puzzlement, surprise, astonishment, frustration, embarrassment or anger." Or it might yield "interactive conflict, cultural friction, communication breakdown, unfair and unjustified attribution of personality traits with subsequent negative labelling and stereotypes". Deviations from the expected or "usual communicative practices in a community or sociocultural group are judged differently depending on the degree of error or flaw perceived" (Riley, 2006: 314).

Giving reference to pragmatic failure in cross-cultural conversation, Ziran and Xinren (2004: 52-7) aver that pragmatic deviation occurs "under the following four circumstances"

a. "The speaker chooses an inappropriate topic. Different cultures usually have different beliefs, value views and living habits. Therefore, people need to distinguish between free and constrained topics in intercultural communication."

b. "The speaker uses expressions which have different implications in the target language, or which deviate from his own intention in producing such utterances. This kind of pragmatic failure commonly happens in greetings. Besides, misuse of fixed expressions in the target language also gives rise to misunderstanding."

c. "The utterance made by the speaker to express a certain idea does not conform to the convention of the target language. Since people with different cultural backgrounds tend to use different expressions and strategies to convey the same information, they tend to commit pragmatic failure while speaking a language other than their mother tongue."

d. "A participant in a conversation makes an inappropriate response to a certain question or statement."

However, two kinds of pragmatic deviation are often recognized: Pragma-linguistic and Socio- pragmatic.

\subsection{Socio-pragmatic Deviation}

Socio-pragmatics is often recognized as "the sociological interface of pragmatics", linked to the "social perceptions underlying participants' interpretation and performance of communicative action". Particularly, socio-pragmatics is concerned with "how pragmatic principles operate in different cultures, in different social situations, among different social classes ... including knowledge of degrees of relative power, social distance, and degree of imposition" (Leech, 1983:10).

Elaborately, socio-pragmatics refers to "the way conditions on language use derived from the social situation". It contrasts with a vision of "pragmatics in which language use is studied from the viewpoint of the structural resources available in a language" (i.e. pragma-linguistics). A pragmalinguistic approach concerns the manner in which language users select various "forms to express a range of attitudes and relationships" (e.g. deference and intimacy) (Crystal, 2008: 441). He (ibid) affirms that the communicative use of language must depend on "shared (public) rules and contexts, to ensure comprehensibility".

Actually, socio-pragmatic deviation stems from "different cultural norms and pragmatic principles that govern linguistic behaviors in different cultures". Most problems of understanding seem to come from "what is identified as differences in evaluation regarding 'size of imposition', 'cross-culturally different assessments of relative power or social distance', and 'value judgments' ". Various cultures exhibit various "ways of thinking, rules of speaking, social values and place different relative weights on the pragmatic principles", and the various evaluations of social restrictions have adversely influenced nonnative speakers' linguistic varieties. Accordingly, this will lead to socio-pragmatic deviation (Thomas, 1983: 91-4). 
This view is highlighted by Ziran and Xinren (2004: 52-7) who maintain that socio-pragmatic deviation arises "when the speaker does not give attention to the identity and social status of the listener during the conversation". He/she may yield pragmatic deviation by utilizing a polite utterance towards "a close person or someone of a lower social status or by addressing a remote person or someone of a higher social status with an intimate form". Here, the speaker's absence of sociopragmatic understanding about "the politeness principle of social interaction" is a chief source of socio-pragmatic deviation. Put simply, Carter and Nunan (1999: 102) expound that this deviation occurs owing to "the social circumstances surrounding the speech act, such as the social distance, politics, religion, morals, gender, power and the closeness of relationships between the interactants, i.e., knowledge about the world." In this case, the speaker fails to know "what to say, when, why and to whom". They (ibid) clarify their point of view stating that not recognizing "the pragmatic force of a 'thank you' might cause a pragma-linguistic failure, but cultural differences of when to say it, in which occasion and for what reason" might lead to socio-pragmatic deviation.

\subsection{Pragma-linguistic Deviation}

To make a distinction between speaker's knowledge about the world and society, and speaker's linguistic knowledge, Strazny (2005: 869872) draws a distinction between pragmalinguistics and socio-pragmatics affirming that pragma-linguistics is concerned with "the verbal resources available for realizing any given speech act". Conversely, socio-pragmatics focuses on "the polite norms governing the selection of resources relative to social situations". As an illustrative example, pragma-linguistics specifies the "word choices, meaning patterns, and sentence constructions" manipulated to express compliment; socio-pragmatics specifies "who may compliment whom, on what, and in which situations". In brief, pragma-linguistics is "language specific" whereas socio-pragmatics is "culture specific".
Pragma-linguistic deviation, Ziran and Xinren (2004: 52-7) postulate, happens when a language user deviates or fails to transfer his/her meaning since "the message's pragmatic force is misunderstood". He/she might interpret a thing from an L1 into an L2, paying no attention to the conversational norms and standards of an L2, which are rather dissimilar. For instance, both the formulaic expressions 'How are you?' and 'Hello' are used to show greeting; pragma-linguistic deviation occurs when "learners sometimes fail to get the meaning of an utterance due to the fact that the communicative conventions behind such an utterance used are different". In this sense, pragmalinguistic is not mainly concerned with speaker's awareness of "what constitute appropriate behavior". Further, it is greatly associated with recognizing "how to phrase an utterance" (e.g. command or request).

Giving reference to the speaker's linguistic competence, Thomas (1983: 91) writes that pragma-linguistic deviation happens when the

"pragmatic force mapped by the speaker
onto a given utterance is systematically
different from most frequently assigned
to it by native speakers of the target
language, or when conversational
strategies are inappropriately
transferred from the speaker's mother
tongue to the target language"

\section{Speech Acts in EFL Classroom}

Approaches to language teaching demonstrate that EFL teachers can effectively interpret the allegedly secret rules for classroom learners and that teaching pragmatics, in this respect, can be fruitful. Teaching pragmatics can show the learners' capability of linking utterances to contexts in which they are used. Hence, Stalnaker (1972:383) explains that pragmatics is "the study of linguistic acts and the contexts in which they are performed". Further, teaching pragmatics may help to enable the student to discover socially suitable language for the circumstances he/she meets, as pragmatics 
involves "the study of the way in which language is used to express what somebody really means in particular situations, especially when the actual words may appear to mean something different" (Hornby, 2001: 990).

Moreover, EFL learners reveal important variances from L2 speakers in the use of language, particularly in understanding and producing speech acts, i.e. in conveying communicative purposes, for instance "greetings and leave-takings, and in conversational management such as back channeling and short responses" (Kasper and Rose, 1999:89ff). Cumulative studies devoted to the description of the use of language in different English-speaking societies have produced significant evidence for teaching pragmatics in ESL/EFL classrooms (e.g. Bardovi-Harlig, 2001).

In theorizing and teaching EFL, speech acts play a vital role since these act increase the awareness of in what way "a language works when used by interlocutors in different contexts". As matter of fact, an EFL language learner must have, in succession, "a good grammatical and lexical command and succeed in communicating functionally", a successful EFL teacher must emphasize on increasing "both competences in order to make a student be successful in foreign language acquisition and usage" (Rathert, 2013: 812). In other words, EFL teachers must have good knowledge about the speech acts and the fundamentals to practice "the natural input for the students in a particular content, for a particular purpose, and as part of a strategy" (Bardovi- Harlig, 1996: 23).

\section{Methodology}

This section involves three phases: the method followed, the sample chosen and the main instrument.

i- Method: The researcher manipulates a qualitative method to describe and analyze his data. The data are collected from responses given by the Iraqi EFL college students on the production test administered to them during the second term of the academic year 2018-2019. The data analysis is based on the pragmatic investigation of the students' answers to the test. Results analysis is made in terms of statistical tools used for measuring students' number, type and percentage of errors committed by the students.

ii- Sample: The sample consists of 50 fourth year students of the University of Baghdad, College of Languages, Department of English. The reason behind selecting fourth year students is that they are expected to acquire good knowledge concerning pragmatic behavior, particularly of speech acts, as they come across such topics in Linguistics and Grammar courses during the fourth years of their BA stage.

To avoid any side effect on the test and to guarantee the homogeneity of the testees, certain variables are taken into consideration in order to obtain effective results. These variables include learners' age, the students nearly seem of the same age; parents' level of educational background.

Instrument: The main tool utilized in the research is a production test consisting 5 items of condolence. In fact, the test contains five spoken situations implying the employment of the expressive speech act condolence to be produced by the students.

\section{Data Collection and Discussion}

Students' answers to the production test are collected and analyzed detecting the number of the correct and incorrect answers to each item that the subjects have made. Finding reasons and justifications behind the socio-pragmatic deviation of condolence is introduced with the aim of arriving at the main findings using suitable percentages. The following table reveals the number of the correct responses of each item of producing condolence with their percentages:

Table 1: Production of Condolence

\begin{tabular}{|c|c|c|}
\hline Item No. & $\begin{array}{l}\text { Correct } \\
\text { Responses }\end{array}$ & Percentage \\
\hline 1 & 17 & $\mathbf{3 4 \%}$ \\
\hline 2 & 10 & $\mathbf{2 0 \%}$ \\
\hline
\end{tabular}




\begin{tabular}{|c|c|c|}
\hline $\mathbf{3}$ & $\mathbf{1 9}$ & $\mathbf{3 8 \%}$ \\
\hline $\mathbf{4}$ & $\mathbf{1 6}$ & $\mathbf{3 2 \%}$ \\
\hline $\mathbf{5}$ & $\mathbf{2 0}$ & $\mathbf{4 0 . \%}$ \\
\hline Total & $\mathbf{8 2}$ & $\mathbf{3 2 . 8 \%}$ \\
\hline
\end{tabular}

Tables (1) above reveals that all the items given seem to be difficult to students, as students record 82 correct answers (constituting 32.8\%) out of 250 answers. It appears that item 5 achieves the highest frequency of correct answers (20 with a percentage of $40 \%$ ). Item 2 is the most difficult one as only 10 students (having a rate of 20\%) are able to produce the proper utterances of condolence. The students' awkwardness of the production of the test may be owing to the unusualness of condolence to them. Most students might not have experienced condolence in their four stages of study.

\section{Sources of Pragmatic Deviation}

With reference to the above table, it has been noticed that Iraqi EFL learners have displayed several defects and inefficiencies as far as their performance of the spoken utterances of condolence is concerned. In general, those learners deviate from the socio-pragmatic norms and principles, owing to two main resources (sociopragmatic and pragma-linguistic).

\subsection{Socio-pragmatic}

Socio-pragmatically, two main factors affect students' answers: The influence of L1 culture and Lack of the social norms and principles of the target culture. They will be explained through the following illustrative examples taken from condolence. Concerning the socio-pragmatic factor, students attempt to produce the required spoken situations but use their L1 socio-pragmatic resources because of the direct influence of L1 pragmatics. This might be interpreted as the attempts of learners to produce the spoken situations relying on their L1 socio-pragmatic information. It is apparent that EFL learners might be unacquainted with the societal, cultural and pragmatic manners of the L2, which are entirely dissimilar from that of the native language. Moreover, aspects of cultural norms, principles and rules of L1 cannot be appropriate or applicable to the norms, principles and rules of L2. The following are some illustrative examples.

In item (2) "On the death of your close friend's daughter ", students reflect their attitudes towards such situations; they guess that they produce utterances of condolence such as "That's our life'. You must be sad man now, so sorry "which do not sound condolences at all. Because of the interference of L1 culture, students give a straight translation related to everyday situations and activities, mistakenly giving apology for condolence. Principally, the students' improper interpretation occurs owing to their absence of socio-pragmatic knowledge of the L1. In other words, they seem to be unaware of the principles initiated for the issuance of the speech act of apology and condolence.

Negative transfer takes place since "the L1 forms, norms or principles used in TL production are not part of the TL forms, norms or principles". Hence, "the resultant utterance is erroneous" (Johnson and Johnson, 1999: 354). Sociopragmatic interference comes about when EFL students duplicate from L1 to L2 their social and traditional and pragmatic information. In some cases, they attempt to overgeneralize L1 sociopragmatic characteristics, principles and standards and exploit them in solving problems in L2 .

To provide more illustration, consider item (5) "Condole your relative whose mother has died recently". This example also reveals that Iraqi EFL students are mostly unacquainted with these utterances and probably they have not experienced them in their fourth stages of learning English. They give incongruent utterances for condolence such as "I am so sad, God is merciful and we all dead". Actually they couldn't understand the situation and therefore give such incompatible utterances.

Nearly, in all the wrong answers, the students seem to resort to their native social norms and traditions which cannot be made relevant or 
correlate to the illocutionary act of apology. Besides, they regularly employ the literal meaning to provide their answers, ignoring the associated pragmatic and suitable meaning an utterance exhibits in terms of the context in which it occurs. Moreover, they attempt to translate from Arabic into English irrespective of the fact that English and Arabic are completely two different languages surrounding by two different circumstances, obeying different social and cultural norms, conventions, principles and rules.

\subsection{Pragma-linguistic Factor}

Pragma-linguistic knowledge involves "mappings of form, meaning, force and context" (Kasper, 2001: 51). It is concerned with "which particular linguistic choices can be used to express different types of meaning". The unfitting utilization of the linguistic forms makes students deviate from the appropriate pragmatic utterance in correlation with the given situations; and the expressive condolence found in theL2 circumstances. The students' improper use of linguistic items is mainly ascribed to particular unsuitable semantic and syntactic characteristics when giving answers. More elaborately, this inappropriateness is basically resulted from the use of improper or unfitting linguistic forms. As a result, imprecise or odd performance of condolence utterances might be made.

In certain situations, students' pragmatic deviation can be attributed to pragma-linguistic knowledge students' lack, particularly when they are unable to catch the meaning of a given utterance owing their inappropriate perception of the communicative principles surrounding this utterance. The obvious illustration of pragmalinguistic deviation can be elucidated via item 1:

\section{Item 1: You are at a funeral and run into the father of the dead.}

It seems that most subjects have given uncertain or awkward explanation linked to the opinion that they have not perceived what these situations are envisioned to deliver, as they are unable to link linguistic forms to the pragmatic meaning of an utterance. They are probably unaware of the idea that it is inadequate to be dependent on linguistic meaning to get at the intended utterance meaning. An examination of the responses given by the students discloses that Iraqi EFL students have taken the given situations literally, paying no attention to their contextual considerations. That is, they have not viewed them as issuing the expressive condolence. Hence, it is conceivable that students depend on certain given words in the situation and to reply for apology for condolence (such as meeting someone at a funeral, giving utterances "I am so sad now", and "we all dead") and neglecting the other possible pragmatic meanings of these utterances.

Similarly, in item (4),"You hear that your dearest friend has lost all her money", getting involved in the idea of hearing about the friend's loss respectively, students give utterances which do not match the given situations. They seem to be bound to the words constituting this situation neglecting the pragmatic considerations directing these situations. For condolence, they give utterances such as "You really losed your money" and "I am sorry to loss money ". They seem to give statement about the loss of the money rather than giving condolence. Such deviation in producing inappropriate utterances may be ascribed to their lack of pragma-linguistic knowledge. They cannot relate semantic ( or even syntactic) knowledge to pragmatic knowledge and this leads to their inability to produce appropriate utterances.

Once more, the students' deviation is connected to their mismatching the syntactic and semantic knowledge to the pragmatic one, leading to pragma-linguistic deviation. Students' incompetency of linguistic knowledge is pertinent to their deficiency of their knowledge of syntax and semantics which results in incongruous expressive condolences. This linguistic deficiency involves certain linguistic misuses such as 'incorrect tenses, prepositions and articles', as well as deficiency in meanings or misunderstanding the conveyed meanings. This signifies that the students' 
repertoire of the linguistic competence is deficient. The students' construal of the situations and production of utterances related to the speech act condolence is realized as clumsy and hesitant, and sometimes this leads students to give to incomprehensible replies.

\section{Conclusion}

In view of the analysis of students' responses to the items of the test, few conclusions have been postulated. They are:

1- Iraqi EFL students face difficulty and deviate in producing the expressive speech act of condolence. This deviation is ascribed to two factors: sociopragmatic and pragma-linguistic competence of the Iraqi EFL university students.

2- Iraqi EFL students' socio-pragmatic deviation, while trying to produce condolence, is primarily linked to their lack of both socio-pragmatic and pragma-linguistic knowledge. The socio-pragmatic deviation has been ascribed to the interference of the students' L1 culture. This type of deviation has brought about non-native production of the speech act of condolence. Most deviant condolences have been presented as straight translations of students' $\mathrm{L} 1$ culture into the $\mathrm{L} 2$.

3. The pragma-linguistic deviation is attributed to the fact that students are unable to connect grammatical (particularly syntactic) knowledge to pragmatic knowledge to arrive at the intended meaning of condolence.

4. Various answers have revealed senseless interpretations due to the students' pragmatic incapability to construe the circumstances that demand condolence and the outcome is non-native utterances for condolence. Yet, other answers have revealed that they are unable to get the meanings of some of items existed in the situations given. Therefore, they have produced replies associated with meanings that are not linked to these situations.

\section{Recommendations}

On the basis of the conclusions above, some pedagogical recommendations can be made useful for EFL teachers, students, syllabus designers and text-book writers.

1. Instructors and teachers should encourage and motivate EFL learners to practice English as much as possible trying to make such a practice regular through the years of study, inside and outside the classroom where students might talk to each other using English. Such a practice might develop the communicative ability of the students' TL and hence leading to appropriate and fluent recognition and production of speech. Accordingly, they can get used to the TL pragmatic knowledge.

2. It is so necessary to focus on the EFL students' linguistic knowledge, and to improve their communicative and pragmatic knowledge. Moreover, increasing the learners' perception levels of appropriateness and pragmatics in the L2 can be attained by inspiring the input of teaching classes with everyday practical resources, related to the oral exchanges of native speakers and television and radio programs. Further, it is significant for EFL teachers to evaluate their students' growth in the area of pragmatics, and be willing to concentrate on teaching pragmatics. Then, teachers must take into account communicative and pragmatic practice and training programs devoted to paying visits to schools, institutes and colleges in the native countries.

3. More attention should be given to increase the vocabulary of the students and to make them use such words more often. Students might be continuously encouraged and motivated to explain the meanings or to put them in sentences that are related to different spoken situations including the production of different illocutionary acts.

4. EFL learners should be taught different syntactic rules and practice different types of sentences that are related to the illocutionary acts. A continuous review of the syntactic rules should be given more attention to refresh students' 
memory and thus developing their communicative and pragmatic competence.

\section{References}

[1] Allan, K. (1998). "Meaning and Speech Acts." Linguistics Program, Monash University

.arts.monash.edu.au/ling/speech-actsallan.html\#n1.

[2] Austin, J. L. (1962). How to do Things with Words. Cambridge, MA: Harvard University Press.

[3] Bach, K. and R. Harnish (1979). Linguistic Communication and Speech Acts. Cambridge: MIT Press.

[4] Bardovi-Harlig, K. (1996). "Pragmatics and Language Teaching: Bringing pragmatics and pedagogy together". Pragmatics and Language Learning, 7, 21-39.

[5] -------- (2001). Evaluating the empirical evidence: Grounds for instruction in pragmatics? In Pragmatics and Language Teaching, eds. K. Rose and G. Kasper. Cambridge: Cambridge University Press.

[6] Black, E. (2006). Pragmatic Stylistics. Edinburgh: Edinburgh University Press.

[7] Çakir, I. (2006). "Socio-Pragmatic Problems in Foreign Language Teaching". Journal of Language and Linguistic Studies. Vol.2, No. 2: 136-146.

[8] Carter, R. and Nunan, D. (eds.) (2001). The Cambridge Guide to Teaching English to Speakers of Other Languages. Cambridge: Cambridge University Press.

[9] Crystal, D. (2008). The Cambridge Encyclopedia of Language, Cambridge: Cambridge University Press.

[10] -------- (2009). A Dictionary of Linguistics and Phonetics ( $2^{\text {nd }}$ ed.) Oxford: Basil Blackwell Ltd.

[11] Dascal, M. (1985). "Language Use in Jokes and Dreams: Sociopragmatic vs. Psycholinguistics". Language and Communication. Vol. 5, No. 2

[12] Fitzgerald, H. (2003) "Writing a Condolence Note." American Hospice
Foundation Home Page. Washington, DC 20037. http://www.americanhospice.org.

[13] Guanlian, Q. (2002). Pragmatics in Chinese Culture. Beijing: Tsinghua University Press.

[14] He, Ziran (2006). Notes on pragmatics. Nanjing: Nanjing Normal University Press.

[15] Hornby, A. S. (2001). Oxford Advanced Learners' Dictionary, Oxford: Oxford University Press.

[16] Hurley, D. S. (1992). Issues in teaching pragmatics, prosody, and non-verbal communication. Applied Linguistics 13(3). 259-281.

[17] Johnson , K. and Johnson, H. (1999). Encyclopedic Dictionary of Applied Linguistics. Oxford: Blackwell Publishers.

[18] Kasper, G. (2001). The Role of Pragmatics in Language Teacher Education. New York: McGraw- Hill.

[19] Kasper, G. and Rose, K. (1999). "Pragmatics and SLA". Annual Review of Applied Linguistics, 19, pp. 81-104.

[20] Leech , G. (1983). Principles of Pragmatics . London : Longman.

[21] Lotfollah, B. and Rasekh, A. (2011). "Speech act of condolence in Persian and English". Studies in Literature and Language. 3, (3), pp. 139-145.

[22] Mey , J. (2001). Pragmatics: An Introduction, $2^{\text {nd }}$ ed. Oxford: Basil Blackwell Ltd.

[23] Mwihaki, A.(2004). "Meaning as use: a functional view of semantics and pragmatics". Swahili Forum, 11, 127-139.

[24] Norrick, Neal R. (1978). "Expressive illocutionary acts". Journal of Pragmatics, 2(3): 277-291.

[25] Nunan, D. (1999). Second language teaching and learning, Boston MA: Heinle \& Heinle Publishers

[26] Rathert, S. (2013). "The Language Outside and Inside the Foreign Language Classroom: Speech Act Theory and Discourse Analysis" The Internet Journal Language, Culture and Society, 36: 81-87. 
[27] Riley, P. (2006). "Self-expression and the negotiation of identity in a foreign language". International Journal of Applied Linguistics, 16(3), 295-318.

[28] Searle, J. R. (1969). Speech Acts. An Essay in the Philosophy of Language. Cambridge: Cambridge University Press.

[29] ---------- (1976) " A Classification of Illocutionary Acts". Language in Society. Vol. 5, No. 1, pp.1-23.

[30] -------- (1979). Expression and Meaning. Cambridge: Cambridge University Press.

[31] Searle, J. R. and Vanderveken, D. (1985). Foundations of illocutionary logic. Cambridge: Cambridge University Press.

[32] Stalankar, R. C. (1972). "Pragmatics". In Semantics of Natural Language, eds. D. Davidson and G. Harman. Dordrecht: Reidel.

[33] Strazny, P. (ed.) (2005). Encyclopedia of Linguistics. V. 1. New York: Fitzroy .

[34] Taavitsainen, I. and Jucker. A. H. (2010). "Expressive speech acts and politeness in eighteenth century English". In R. Hickey (ed.). Eighteenth Century English: Ideology and Change, 159-181. Cambridge: Cambridge University Press.

[35] Taylor, M. V. (1978). The Grammar of Conduct: Speech Act Theory and the Education of Emma Woodhouse, Style. vol. 12: pp. 357-

[36] Thomas, J. (1983). "Cross-cultural Pragmatic Failure". Applied Linguistics, 4: 91-112.

[37] Yahia, E. (2010). "A study of condolences in Araqi Arabic with reference to English". Baghdad: Adab Al-Rafidayn, 57, 47-70. http://www.arts.monash.edu.au/ling/speech -acts-allan.html\#n1.

[38] Yule, G. (1996). Pragmatics. Oxford: Oxford University Press.

[39] Ziran, H. and Xinren, C. (2004). Contemporary Pragmatics. Beijing: Foreign Language Teaching and Research Press.
[40] Zunin , L. M. and Zunin , H. S . ( 2007). The Art of Condolence . London: Harper Collins Publishers Ltd.

\section{The Test}

$Q /$ What will you say in the following situations:

1. You are at a funeral and run into the father of the dead.

2. On the death of your close friend's daughter.

3 . Your eldest brother's son has died.

4. You hear that your dearest friend has lost all her money.

5. Condole your relative whose mother has recently died. 